\title{
Demographic predictors of depression influencing quality of life among renal transplant recipients
}

Kamran, Fatima $\square$

University of Surrey, United Kingdom (f.kamran@surrey.ac.uk)

Lecturer, Department of Applied Psychology, University of the Punjab, Lahore, Pakistan

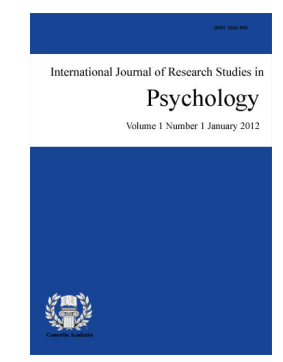

ISSN: 2243-7681 Online ISSN: 2243-769X

OPEN ACCESS

\section{Abstract}

A longitudinal study was carried out to investigate the impact of depression levels on satisfaction with Quality of Life (QoL) after renal transplantation. Renal transplant recipients (RTRs) were assessed at three times over a period of 15 months in Lahore (Pakistan). Our study aimed to analyze if QoL and perceptions of it are likely to be influenced by their level of depression and analyze the demographic correlates and predictors of depression among RTRs. The cross lagged panel showed that across all three waves, depression levels appeared to be strong predictors of QoL satisfaction. The study attempted to explore causal priority of relationships among depression and QoL to clarify if QoL is an outcome of depression or vice versa. Gender, age, marital status, and low family income appeared to be significant predictors of depression among RTRs.

Keywords: depression; Quality of Life; renal/kidney transplantation; demographic factors; predictors of depression; longitudinal study 


\section{Demographic predictors of depression influencing quality of life among renal transplant recipients}

\section{Introduction}

Kidney transplant improves quality of life (QoL) in patients with renal failure, as compared to dialysis but recipients report a number of challenges causing distress. Negative emotional states are the single most influential factor in determining quality of life after a successful kidney transplant (Baines, Joseph, \& Jindal 2002). Depression is associated with decreased QoL and increased morbidity and mortality in patients with end-stage renal disease (E.S.R.D). Dobbels (2008) reported that depression is associated with double the risk of kidney failure, return to dialysis and death among the studied kidney transplant recipients, the researcher found that the incidence of depression was about $7 \%$ the first year after transplantation, $11 \%$ in the second year and $13 \%$ in the third year. Kidney failure occurred in $19 \%$ of the patients, $8 \%$ died with a functioning kidney and $11 \%$ had to return to dialysis therapy (http://www.mikedubrick.com/mtp.com/depression07.htm).

Depression can lead to poor health outcomes after kidney transplantation (Szeifert, Molnar, Ambrus, Koczy, Kovacs, Vamos , Keszei, Mucsi, \& Novak 2010). Therefore, depression screening is essential to identify vulnerable recipients who need psychological management. Screening for anxiety and depression in kidney transplant recipients is essential. Appropriate treatment may improve various aspects of patient well-being, including quality of life, sleep, marital relations, and sexual relationship (Noohi, Khaghani-Zadeha, Javadipourb, Assarib, Najafia, Ebrahiminiaa, \& Pourfarziania, 2007). Achille, Ouellette, Fournier, Vachon, and Héber (2006) found that uncertainty about future health and finances and side effects of medications cause significant psychological strain after transplant. There are limited studies exploring depression among renal transplant recipients, therefore, Szeifert, Molnar, Ambrus, Koczy, and Kovacs et al. (2010) analyzed whether decreasing graft function, co morbidities, age, sex, or socioeconomic status are associated with depressive symptoms in kidney transplant recipients. They found that the prevalence of depression was $33 \%$ versus $22 \%$ in waiting-list control versus transplant patients, respectively and a number of comorbid conditions, including; estimated glomerular filtration rate(GFR), perceived financial situation, and marital status were significant and independent predictors of depression in the transplant recipient group.

In a recent large retrospective study, cumulative incidences of clinically diagnosed depression were 5\%, 7\%, and $9 \%$ at 1, 2, and 3 years after kidney transplant (Dobbels, Skeans, Snyder, Tuomari, Maclean, \& Kasiske 2008). Rocha, Poli deFigueiredo, d'Avila, and Saitovitch (2001) found that RTRs with moderate-to-severe depressive symptoms had an increased risk for negative transplant outcome (chronic allograft nephropathy, death censored graft loss, or death) compared with non-depressed recipients. Existing literature highlights the significance of investigating and identifying depressive symptoms among this group is emphasized to facilitate timely treatment. Depressive symptoms are found to be an independent predictor of mortality in renal transplant recipients (Novak, Molnar, Szeifert, Kovacs, Vamos, Zoller, Keszei, \& Mucsi, 2010).

\subsection{Research question}

Do depression levels predict QoL satisfaction among renal transplant recipients?

\section{Method}

\subsection{Study design}

A longitudinal study was carried out in Lahore (Pakistan) comprising of RTRs, with ages ranging from 
18-54 years, from diverse geographical regions of Pakistan recruited from the renal clinics in Lahore. These patients had a post-transplant period ranging from 6 months to 5 years and with normal graft functioning.

\subsection{Participants and recruitment}

> Inclusion criteria: Renal transplant recipients currently on a schedule of regular follow-up appointments; age range of 18-54 years without any co-morbidity (existing physical or mental disorders); not more than one previous transplant, minimum basic formal schooling to equivalent of primary school level, and healthy graft functioning as indicated by follow up monitoring of renal function tests.

$>$ Exclusion criteria: Renal transplant recipients with medical co-morbidities or complications and/or psychological disorders; outside the age range 18-54, recipients with no formal schooling; more than two kidney transplants in total, or any other co-existing transplant e.g., liver, heart or lung transplant along with a kidney transplant.

$>$ Measures : Demographic information collected included age, gender, marital status, years of formal education, employment status, household income and number of dependents, familial background (rural/urban), and family system i.e. joint or nuclear. Medical information collected included basic clinical information about approximate onset and duration of end stage renal disease (ESRD), dialysis modality (hemodialysis, peritoneal or both) before transplant and duration of dialysis, primary \& secondary nephrologic diagnosis to reveal the etiology of renal failure, time since transplant, current medication (immunosuppressant group and dosage), complete blood profile with renal functions (including, serum creatinine, blood urea, uric acid).

\subsection{Quality of Life Index Kidney Transplant version 111 (1998)}

The QoL index developed by Ferrens and Powers (1998) consists of 35 items and measures both the satisfaction with, and importance of, the main domains of life. Importance ratings are used to weight the satisfaction responses so that the scores reflect the respondents' satisfaction with the aspects of life they value. Scores are calculated for QoL overall and in four domains: health and functioning, psychological/ spiritual, social and economic, and family. Items that are rated as more important have a greater impact on scores than those of lesser importance. Satisfaction is rated from 1 = "very dissatisfied" to 6 = "very satisfied", and importance is rated from 1 = "very unimportant" to $6=$ "very important". Scores range from 0-30 and are calculated by weighting each satisfaction response with its paired importance response. Overall (total) scores and the four subscale scores, health and functioning, social \& economic, psychological and spiritual, and family scores are calculated (Ferrans, 1990, 1996; Ferrans \& Powers, 1992, 1996; Warnecke, Ferrans, \& Johnson, 1996).

\subsection{Beck Depression Inventory (BDI- II)}

The Beck Depression Inventory (BDI, BDI-II), is a 21-question multiple-choice self-report inventory and is one of the most widely used instruments for measuring the severity of depression The scores can be related to role limitations due to emotional problems. Each item is responded to on a scale from 0 to 3 , where 0 is for a statement describing minimum feeling regarding an aspect of depression and a score of 3 reflects severe depression. The responses on each dimension are summed and a total score is obtained. This total score is compared with the given cut off scores. The cut offs used are 0-13: minimal depression; 14-19: mild depression; 20-28: moderate depression; and 29-63: severe depression. Higher total scores indicate more severe depressive symptoms. Participants are asked to rate how they have been feeling for the past two week (Beck, Steer, \& Brown, 1996). 


\section{Results}

This three-time longitudinal study investigated the occurrence and demographic differences in depression among RTRs. The study analyzed reciprocal causal relationships between depression levels and QoL satisfaction over time. The aim was to evaluate the strength and causal priority among these variables.

\subsection{Sample characteristics}

The mean age of the study participants was 33.99 years (ranging from 18 to $54, S D=7.45$ ), post transplant time ranged from 6 months to 5 years. For the purposes of the analyses, the recipients living with their spouses or engaged were considered to be in a relationship and those who were separated, widowed, divorced, or never married were considered 'single'. The sample comprised mostly of recipients currently taking three medications, i.e. two immunosuppressant drugs (compulsory for transplant recipients), a conventional drug (cyclosporine) and a newer drug (mycofenolate) along with steroids. Most recipients were highly educated, with a high rate of professional qualification $(\mathrm{N}=66)$ and were mostly in employment $(\mathrm{N}=92)$. There was a lower representation of recipients with a low socioeconomic status (SES; $N=8)$, and most recipients belonged to an average SES $(\mathrm{N}=78)$ determined on the basis of monthly family income.

\section{Table 1}

Demographic characteristics of renal transplant recipients

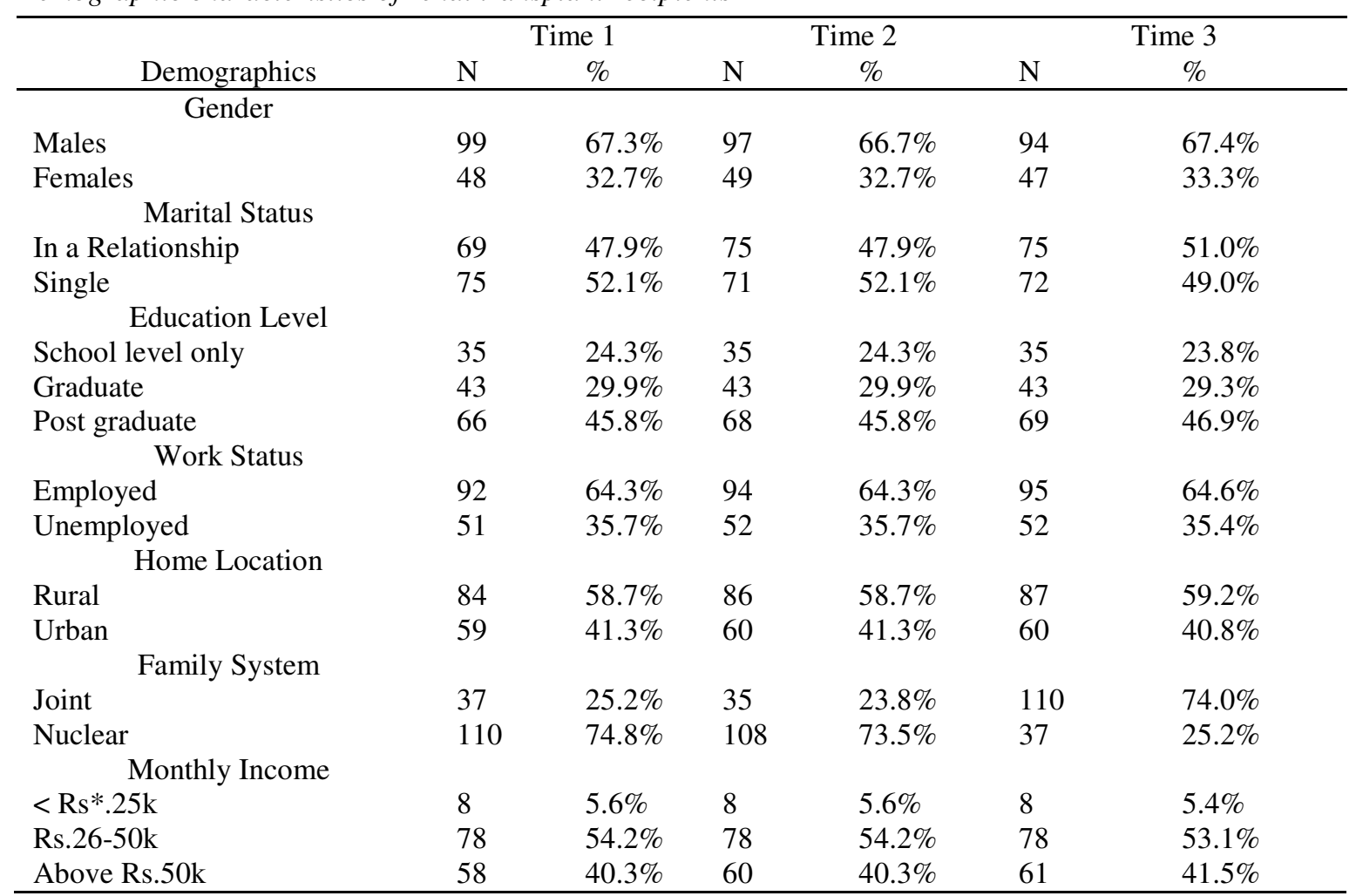

For the purpose of analysis, the longitudinal data were used to examine the contribution of depression levels in predicting QoL after renal transplant over a period of 15 months.

\subsection{Quality of Life after renal transplant}

QoL is conceptualized as a multidimensional phenomenon reflecting an individual's perceptions of physical health status, psychological well-being (happiness and life satisfaction) of individuals as influenced by their demographic, biological, and psychological characteristics, as well as the social, economic, personal, and 
situational variables (Cetingok, Winsett, \& Hathaway, 2004). Therefore, QoL in the present study, was measured as a subjective construct, as individual's perception of his/ her life post transplant by using QoL Index which had scores ranging from 0-35 on four subscales (health functioning, family life, social \& economic conditions and psychological \& spiritual well-being), with higher scores reflecting increased satisfaction with their QoL.

The results across all three times over a period of 15 months indicated that most recipients were satisfied with their QoL after renal transplant and with the passage of time; there was a slight increase in the satisfaction reports as indicated by their mean scores on QoL Index at time 2 and 3 (see table 2).

\section{Table 2}

Total Scores on the QoL Index at Time 1, 2, and 3

\begin{tabular}{lccccc}
\hline \multicolumn{1}{c}{ QoL Scores } & $N$ & Minimum & Maximum & Mean & $S D$ \\
\hline QoL Time 1 & 150 & 12.08 & 35.00 & 23.71 & 3.45 \\
QoL Time 2 & 147 & 16.41 & 29.35 & 23.74 & 2.62 \\
QoL Time 3 & 144 & 17.50 & 29.31 & 24.98 & 2.35 \\
\hline
\end{tabular}

The findings suggest that minor variations do occur in subjective QoL at different points of time, and most RTRs appeared to be satisfied by their life post transplant. The scores on QoL index subscales over a period of 15 months showed that RTRs reported highest satisfaction with their family life, followed by their health functioning, social and economic conditions and lastly psychological and spiritual well-being (see table 3 ).

Table 3

Descriptives of QoL Index subscales

\begin{tabular}{cccccc}
\hline QoL Subscales & $N$ & Minimum & Maximum & Mean & $S D$ \\
\hline *HF Time 1 & 146 & 12.09 & 31.97 & 23.98 & 3.23 \\
HF Time 2 & 145 & 15.88 & 29.47 & 23.80 & 2.85 \\
HF Time 3 & 144 & 17.37 & 29.69 & 24.80 & 2.59 \\
\hline *FS Time 1 & 146 & 17.10 & 30.50 & 27.03 & 3.31 \\
FS Time 2 & 147 & 16.50 & 30.00 & 25.96 & 3.35 \\
FS Time 3 & 144 & 18.00 & 31.67 & 27.08 & 3.14 \\
\hline *SE Time 1 & 146 & 9.93 & 28.21 & 21.09 & 3.55 \\
SE Time 2 & 147 & 12.21 & 28.93 & 22.01 & 3.21 \\
SE Time 3 & 144 & 15.07 & 28.21 & 23.71 & 2.63 \\
\hline *PS Time 1 & 146 & 13.94 & 18.00 & 16.52 & .774 \\
PS Time 2 & 147 & 13.90 & 18.00 & 16.76 & .710 \\
PS Time 3 & 144 & 15.26 & 18.00 & 17.04 & .608 \\
\hline Note. *HF (Health Functioning), *FS (Family subscale), *SE (Social \& Economic), *PS (Psychological \& Spiritual)
\end{tabular}

\subsection{Depression among renal transplant recipients}

The results showed a pattern indicating a reduction in recipients' depression levels with time. The severity of depression seemed to decrease with increasing time since transplantation. Most recipients (94.5\%) at time 1 either reported minimal or mild level of depression with only a few $(4.8 \%)$ reporting moderate and just one case of severe depression. The self-reports of depression improved in time 2 where most recipients reported minimal and mild depression and few reporting moderate depression but not a single case of severe depression. Interestingly, at time 3, all recipients (100\%) either reported minimal or mild depression only. There are no cases reporting moderate or severe depression, indicating an improvement in recipients' affective condition with the passage of time (see table 4). 
Kamran, F.

\section{Table 4}

Depression Scores on B.D.I II at Time 1, 2, and 3

\begin{tabular}{lcccccc}
\hline & \multicolumn{2}{c}{ Time1 } & \multicolumn{2}{c}{ Time 2 } & \multicolumn{2}{c}{ Time 3 } \\
B.D.I Ranges & Frequency & Percent & Frequency & Percent & Frequency & Percent \\
\hline Minimal 0-13 & 101 & 69.2 & 95 & 64.6 & 113 & 78.5 \\
Mild 14-19 & 37 & 25.3 & 40 & 27.2 & 31 & 21.5 \\
Moderate 20-28 & 7 & 4.8 & 12 & 8.2 & 0 & 0 \\
Severe 29-63 & 1 & .7 & 0 & 0 & 0 & 0 \\
Total & 146 & 100.0 & 150 & 100 & 144 & 100 \\
\hline
\end{tabular}

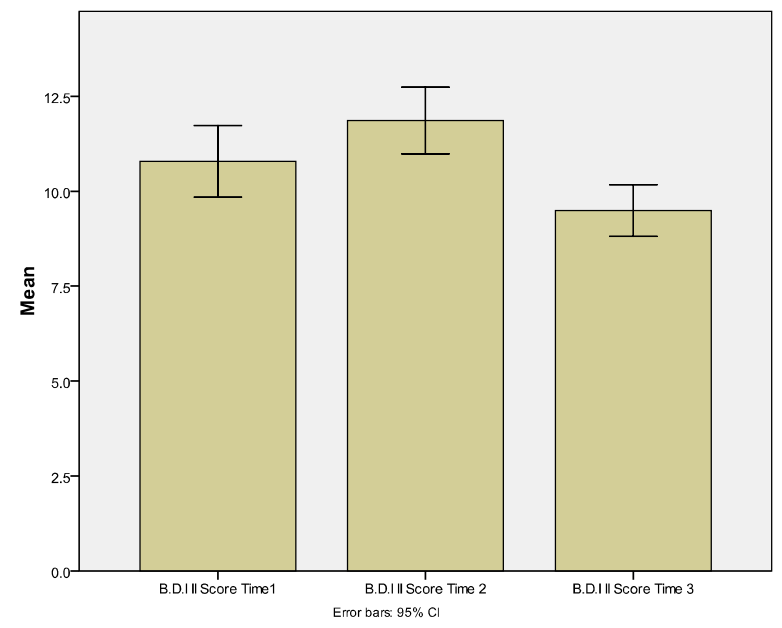

Figure 1. Graph showing occurrence of depression in RTRs at Time 1, 2, and 3

The findings revealed that there are some significant negative correlations in depression and QoL at all three times of assessment (see table 5).

\section{Table 5}

Correlations among Depression and QoL

\begin{tabular}{lccc}
\hline & B.D.I II Score Time1 & B.D.I II Score Time 2 & B.D.I II Score Time 3 \\
\hline QoL Scores Time 1 & $-.689^{* * *}$ & $-.242^{* *}$ & $-.379^{* *}$ \\
QoL Scores Time 2 & & $-.532^{* *}$ & $-.290^{* *}$ \\
QoL Scores Time 3 & & & $-.538^{* *}$ \\
\hline
\end{tabular}
Note. ${ }^{* *} p<.001$

The above table shows significant negative correlations among depression and QoL at all three points of assessment, indicating that recipients who are more depressed tend to report less satisfaction with their QoL. Since, depression can be considered as a potential risk factor for negatively influencing life satisfaction, it is important to identify vulnerable groups of recipients who tend to be more depressed. The study analyzed how demographic factors are associated with depressive symptoms in kidney transplant recipients The study analyzed individual differences psychological consequences post-transplant based on their demographics to find their contribution in influencing over all subjective well-being.

\subsection{Age \& Depression}

Research in transplant outcomes suggests that depression increases with age. (Kusleikaite, Bumblyte, \& Pakalnyte, 2007) reported that depression was associated with a lower QoL. Patients with depression were older and had a worse graft function. The results in our study showed that recipients' age is associated with depression levels. There is a significant positive correlation in age and depression level, time $1, \mathrm{r}=.359, p=<.001$, time $2, \mathrm{r}$ 
$=.529, p=<.001$, and time $3, \mathrm{r}=.445, p<.001$. The results suggest that depression increases with age and older recipients tend to be more depressed than younger ones.

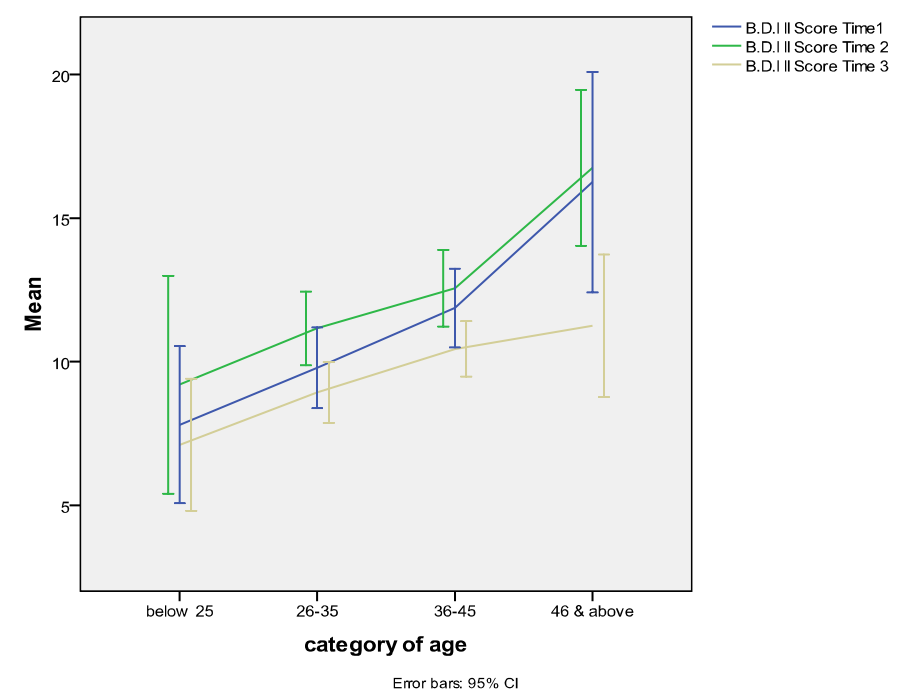

Figure 2. Age groups and mean scores B.D.I II, Time 1, 2, and 3

The above graph clearly reflects that depression levels tend to increase with recipients' age. A visible difference is indicated particularly between recipients below the age of 25 years and those above 46 years. Younger recipients tend to be less depressed as compared to older ones. There are significant positive correlations in recipients' age and their depression levels at each time of assessment.

The results showed that depression and age at all three times were significantly correlated, (time $1, \mathrm{r}=.359$, $p<.001$, time $2, \mathrm{r}=.358, p<.001$ and time $3, \mathrm{r}=.311, p<.001)$ suggesting that depression levels increase with age. Older recipients tend to report increased depression as compared to younger recipients.

\subsection{Gender differences in depression}

There are significant gender differences found at all three points of assessment. Females appeared to be more depressed throughout the study as compared to male recipients (see table 6).

\section{Table 6}

Gender differences in depression among RTRs at time 1, 2, and 3

\begin{tabular}{lccccccccc}
\hline B.D.I II Scores & Gender & $N$ & Means & $S D$ & $t$ & $d f$ & Sig & $d$ & $r$ \\
\hline Time 1 & Male & 98 & 10.14 & 5.00 & -2.169 & 144 & .032 & -0.36 & -0.18 \\
& Female & 48 & 12.25 & 6.44 & & & & & \\
Time 2 & Total & 146 & 10.84 & 5.58 & & & & \\
& Male & 97 & 11.05 & 5.02 & -2.829 & 145 & .005 & -0.48 & -0.23 \\
& Female & 47 & 13.53 & 5.27 & & & & & -0.31 \\
Time 3 & Total & 144 & 11.86 & 5.22 & & & & \\
& Male & 94 & 8.60 & 3.61 & -3.871 & 142 & .000 & -0.66 & \\
& Female & 47 & 11.23 & 4.29 & & & & & \\
& Total & 141 & 9.48 & 4.03 & & & & & \\
\hline
\end{tabular}

Note. Dependent variable: Depression levels

The findings of our study are in confirmation with previous research (Johnson, Wicks, Milstead, Hartwig, \& Hathaway, 1998) that confirms that female recipients tend to report more depression as compared to male recipients after kidney transplant. 
Kamran, F.

\subsection{Marital status and depression}

Coping and adjustment post-transplant is influenced by their marital status. Individuals in a relationship tend to have an emotional, financial and/or physical support of their partners as compared to singles (White \& Gallagher, 2010). The study aimed to find out whether recipients' marital status influenced their depression levels. In contrast to previous findings, the results showed that the two groups of recipients did not differ in depression. Recipients currently 'in a relationship' did not report less depression as compared to those who were single (never married, separated, divorced and widow) (see table 7).

\section{Table 7}

Marital status and depression

\begin{tabular}{lllllclccc}
\hline B.D.I II Scores & \multicolumn{1}{c}{ Marital Status } & $N$ & Means & $S D$ & $t$ & $d f$ & Sig & $d$ & $r$ \\
\hline \multirow{2}{*}{ Time 1 } & In a relationship & 69 & 10.78 & 5.19 & -.047 & 142 & .963 & -0.00 & -0.00 \\
\multirow{2}{*}{ Time 2 } & Single & 75 & 10.83 & 5.98 & & & & & \\
\cline { 2 - 8 } & In a relationship & 80 & 12.21 & 4.59 & .784 & 145 & .434 & 0.12 & 0.06 \\
Time 3 & Single & 67 & 11.54 & 5.84 & & & & & \\
\cline { 2 - 8 } & In a relationship & 77 & 9.01 & 3.16 & -1.596 & 142 & .113 & -0.26 & -0.13 \\
& Single & 67 & 10.07 & 4.75 & & & & & \\
\hline
\end{tabular}

Note. Dependent variable: Depression levels

Szeifert et al. (2009) also found marital status to be a significant predictor of depression among renal transplant recipients. The present study had a low representation of divorced, widowed and separated recipients, so they were grouped together as 'single'. An equal number of participants in each category of marital status could have clarified if differences in depression levels exist in support of previous research findings.

\subsection{Education and depression}

Education level also affected depression levels and recipients with higher educational backgrounds appeared to be less depressed. It has been found that the severity of depressive symptoms is higher among recipients with lower educational status (Karaminia et al., 2007). The recipients were categorized into three groups according to their formal education. The groups included school-level e, graduate and post graduate recipients. The aim was to find if education plays a positive role in subjective well-being and whether recipients with higher education tend to be less depressed comparatively. Karaminia et al. (2007) found that severity of depressive symptoms was higher among people with lower educational status. The findings of our study confirm those of previous studies that education has an impact on individual's depression level as more educated RTRs appeared to be less depressed than those who were less educated.

\subsection{Employment status and depression}

RTRs ability to resume work and earn is a significant factor that contributes towards his/ her psychological well-being and improvement of QoL. The study explored whether there are differences in depression among those who are employed compared to non working RTRs (e.g. house wives, retired officers, and students). However, depression levels did not differ in the two groups i.e. employed and unemployed or non-working recipients at any time of assessment. The table shows that no significant differences in depression levels were found among recipients based on their work status.

\subsection{Financial conditions and depression}

It is assumed that recipients with a stable and sound financial conditions tend to be less depressed compared to those with minimal sources and difficult financial circumstances. Depression appeared to be reported more among those with less monthly family income at all three times of assessment (see graph). 


\section{Table 8}

Education and depression levels

\begin{tabular}{llllllll}
\hline & Education & $N$ & Mean & $S D$ & $F$ & Sig & $\eta 2$ \\
\hline Time 1 & School level only & 35 & 11.97 & 5.3 & $\mathrm{~F}(2,143)=3.693$ & .027 & .049 \\
& Graduate & 43 & 12.00 & 4.8 & & & \\
& Post graduate & 68 & 9.51 & 5.8 & & & .050 \\
& Total & 146 & 10.84 & 5.5 & & & \\
\cline { 2 - 7 } 2 & School level only & 35 & 12.17 & 4.8 & $\mathrm{~F}(2,141)=3.704$ & .027 & .008 \\
& Graduate & 41 & 13.46 & 5.3 & & & \\
\multirow{2}{*}{ Time 3 } & Post graduate & 68 & 10.74 & 5.1 & & & \\
& Total & 144 & 11.86 & 5.2 & & & \\
\cline { 2 - 7 } & School level only & 33 & 8.93 & 4.5 & $\mathrm{~F}(2,138)=.572$ & & \\
& Graduate & 41 & 9.95 & 3.9 & & & \\
& Post graduate & 67 & 9.46 & 3.8 & & & \\
& Total & 141 & 9.48 & 4.0 & & & \\
\hline
\end{tabular}

Note. Dependent variable: Depression levels

\section{Table 9}

Employment status and depression

\begin{tabular}{|c|c|c|c|c|c|c|c|}
\hline B.D.I II Scores & Work Status & $N$ & Means & $S D$ & $F$ & Sig & $\eta 2$ \\
\hline \multirow[t]{2}{*}{ Time 1} & Working & 94 & 10.56 & 5.66 & $\mathrm{~F}(2,144)=.624$ & .431 & .004 \\
\hline & not-working & 52 & 11.33 & 5.46 & & & \\
\hline \multirow[t]{2}{*}{ Time 2} & Working & 93 & 11.70 & 5.41 & $\mathrm{~F}(1,142)=.252$ & .617 & .002 \\
\hline & not-working & 51 & 12.16 & 4.90 & & & \\
\hline \multirow[t]{2}{*}{ Time 3} & Working & 91 & 9.28 & 3.90 & $F(1,139)=.606$ & .438 & .004 \\
\hline & not-working & 50 & 9.84 & 4.28 & & & \\
\hline
\end{tabular}

Note. Dependent variable: Depression levels
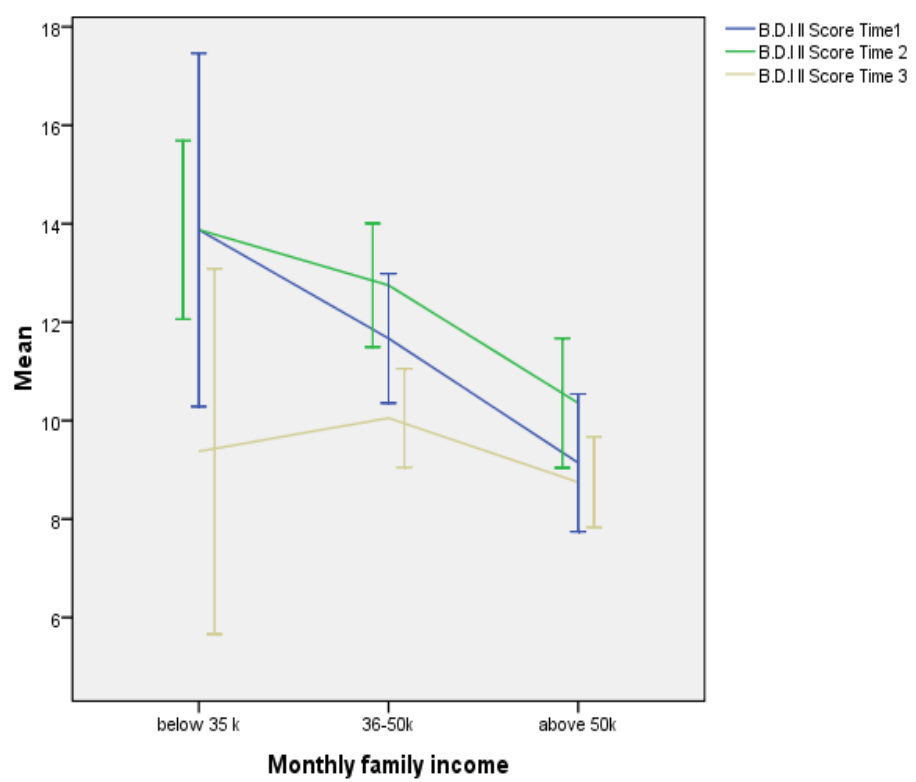

Error bars: $95 \% \mathrm{cl}$

Figure 3. Monthly family income and mean scores B.D.I II, Time 1, 2, and 3 
Kamran, F.

\section{Table 10}

Depression and monthly family income

\begin{tabular}{llcccccc}
\hline B.D.I Score & $*$ MFI & $N$ & Means & $S D$ & $F$ & Sig & $\eta 2$ \\
\hline Time1 & $<$ Rs.35000 & 8 & 13.88 & 4.29 & $\mathrm{~F}(2,143)=4.045$ & .020 & .052 \\
& Rs.36-50000 & 78 & 11.62 & 5.69 & & & \\
Time 2 & $>$ Rs.50000 & 60 & 9.42 & 5.29 & & & \\
& $<$ Rs.35000 & 8 & 13.88 & 2.16 & $\mathrm{~F}(2,141)=3.793$ & .025 & .051 \\
& Rs.36-50000 & 78 & 12.69 & 5.44 & & & \\
Time 3 & $>$ Rs.50000 & 58 & 10.47 & 4.92 & & & .178 \\
& $<$ Rs.35000 & 8 & 9.37 & 4.43 & $\mathrm{~F}(2,138)=1.750$ & .025 \\
& Rs36-50000 & 76 & 10.05 & 4.38 & & & \\
\hline Note *MFI (Monthly Family Income), Dependent variable: Depression levels & & &
\end{tabular}

The findings reveal that although RTRs having different monthly incomes differed in depression levels at time 1 and 2 but not at time 3. Depression levels were lower among recipients with better financial conditions, i.e. more monthly incomes. However, keeping in view the small effect sizes, it cannot be determined whether this difference in depression levels can be associated with their financial conditions.

\subsection{Time since transplantation and depression}

There are significant positive correlations between depression and time since transplantation reflecting that depression increases with time post transplant.

\section{Table 11}

Correlations among depression and time since transplantation

\begin{tabular}{lc}
\hline B.D.I Score & Time since Transplantation \\
\hline Time 1 & $.186^{*}$ \\
Time 2 & $.264^{* *}$ \\
Time 3 & $.254^{* *}$ \\
\hline Note $*^{*} p<.001 * *<.005$ &
\end{tabular}

Note. ${ }^{*} p<.001, * p<.005$

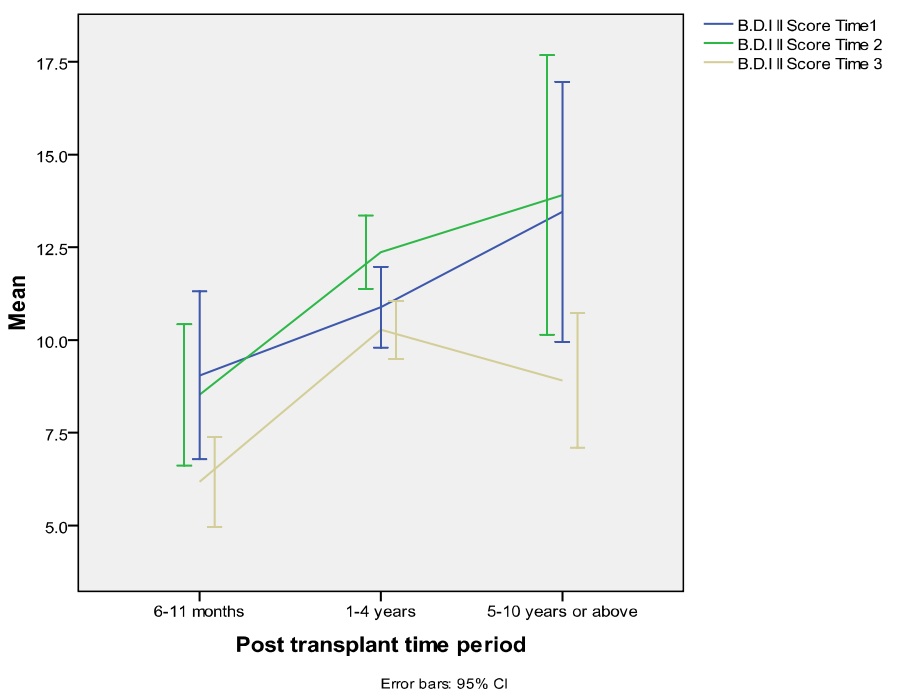

Figure 4. Post transplant time period and mean scores B.D.I II, Time 1, 2, and 3 
Depression levels differed among groups of recipients with according to their time since transplantation. At all three points of measurements, recipients with less time since transplantation (6-11 months) reported less depression followed by group 2 (1-4 years) and the recipients in group 3 (5 years and above) who reported high depression levels comparatively. At time, 1 and 2, depression levels among recipients who had their transplants more than 5 years back, appear to have a similar pattern of increased depression, whereas in time 3, these recipients with five and more years of time since transplantation tend to report less depression (see graph below).

Table 12

Depression among RTRs and time since transplantation

\begin{tabular}{llcccccc}
\hline & Time since *Tx & $N$ & Means & $S D$ & $F$ & Sig & $\eta 2$ \\
\hline Time1 & 6-11 months & 23 & 9.04 & 5.23 & $\mathrm{~F}(2,143)=2.114$ & .077 & .043 \\
& 1-4 years & 110 & 10.91 & 5.63 & & & \\
& 5-10 years \& above & 13 & 13.38 & 5.04 & & & \\
& Total & 146 & 10.84 & 5.58 & & & .085 \\
\cline { 2 - 7 } Time 2 & 6-11 months & 23 & 8.52 & 4.40 & $\mathrm{~F}(2,141)=6.699$ & .002 & \\
& 1-4 years & 109 & 12.39 & 5.11 & & & \\
& 5-10 years \& above & 12 & 13.50 & 5.53 & & & \\
& Total & 144 & 11.86 & 5.22 & & & \\
Time 3 & 6-11 months & 23 & 6.17 & 2.79 & $\mathrm{~F}(2,138)=11.180$ & .000 & \\
& 1-4 years & 107 & 10.25 & 4.02 & & & \\
& 5-10 years \& above & 11 & 8.90 & 2.70 & & & \\
& Total & 141 & 9.48 & 4.03 & & & \\
\hline Note. ${ }^{*}$ Tx: transplant, Dependent variable: Depression levels & & & & \\
\cline { 2 - 6 }
\end{tabular}

The above table shows that at time 2 and 3, depression levels differ among groups of RTRs with different time since transplant, but keeping in view the small effect size, these differences cannot be fully attributed to time since transplantation.

It can be concluded that overall most recipients reported mild to minimum level of depression, indicating a positive affective condition after transplant. The gender female, being single, being older, less educated, and more time since transplantation tend to increase depression among recipients. The results found that RTRs with a stable financial condition, (monthly family income $>$ Rupees $50 \mathrm{k}$ ) reported less depression as compared to those with limited finances (monthly income < Rupees 50k). Interestingly, there was no difference in depression levels of working and non working recipients suggesting that employment status did not affect their mood.

Szeifert et al. (2010) suggested that there is need to explore the clinical and socio-demographic correlates of depression in kidney transplant recipients because it is associated with impaired QoL and increased morbidity and mortality. They concluded that the severity and prevalence of depression are significantly lower in kidney transplant recipients than in wait-listed dialysis patients with similar characteristics which are in confirmation with our findings. Furthermore, they found that socio-demographic factors and co morbidity are independently associated with depressive symptoms in RTRs.

\subsection{Demographic predictors of depression}

The results showed that demographic factors play a significant role in predicting depression among RTRs. Age, gender, marital status, and financial conditions appeared to be significant predictors of depression levels at all three times of assessment, showing a consistent pattern over time (see table 13).

The table shows that recipients' age, gender, marital status and monthly family income reflective of their financial condition have a significant influence on their depression levels consistently at each time of assessment. The analysis of demographic differences in depression level is consistent with this finding. Whereas, education 
Kamran, F.

level and time since transplantation predicting depression at any time of assessment. It suggests that depression is not influenced by recipients' education and time post transplant.

Affective condition of the recipients is considered as an important indicator of their subjective well-being hence influencing their overall QoL. The aim was to find if significant causal relationships occurred between depression and QoL satisfaction. Cross lagged paths between recipients' depression and subjective QoL across time were analyzed in order to clarify causal priority reciprocal and strength of relationships between these two variables. The cross lagged analysis involved a linear regression between depression level at time 1 as predictor of QoL at time 2, and then depression time 2 predicting QoL at time 3. The same analysis was also repeated with reversing the predictor i.e. depression, then as an outcome of QoL, to determine causal priority among these variables. The results showed that there are significant associations found between recipients' depression levels and their subjective QoL across 3 assessments.

\section{Table 13}

Demographic predictors of depression among RTRS

\begin{tabular}{lccccccccc}
\hline \multicolumn{1}{c}{ Predictors } & \multicolumn{3}{c}{ Depression Time 1 } & \multicolumn{3}{c}{ Depression Time 2 } & \multicolumn{3}{c}{ Depression Time 3 } \\
& $\beta$ & $t$ & Sig. & $\beta$ & $t$ & Sig. & $\beta$ & $t$ & Sig. \\
\hline Age & .424 & 5.596 & .000 & .401 & 5.232 & .000 & .435 & 5.666 & .000 \\
Gender & .215 & 2.845 & .005 & .249 & 3.241 & .001 & .294 & 3.816 & .000 \\
Marital status & .280 & 3.989 & .000 & .255 & 3.513 & .001 & .355 & 4.897 & .000 \\
Education & -.119 & -1.610 & .110 & -.059 & -.783 & .435 & .124 & 1.639 & .104 \\
Work Status & .118 & 1.410 & .161 & .075 & .882 & .379 & .116 & 1.377 & .171 \\
Monthly income & -.255 & -3.607 & .000 & -.214 & -2.971 & .004 & -.148 & -2.057 & .042 \\
Time Since & .070 & .980 & .329 & .151 & 2.095 & .038 & .063 & .880 & .381 \\
Transplant & & & & & & & & & \\
\hline
\end{tabular}

Note. Dependent variable: Depression levels

\section{Table 14}

Correlations among depression levels and QoL time 1, 2, and 3

\begin{tabular}{llll}
\hline & QoL 1 & QoL 2 & QoL 3 \\
\hline Depression 1 & $-.689^{* *}$ & $-.372^{* *}$ & $-.336^{* *}$ \\
Depression 2 & & $-.532^{* *}$ & $-.372^{* *}$ \\
Depression 3 & & & $-.538^{* *}$ \\
\hline Note. ${ }^{* *} p<.001$ & & &
\end{tabular}

The above table shows significant negative correlations between depression and QoL, suggesting that the lower the level of depression, the higher satisfaction with QoL. There were significant positive correlations found among recipients' depression levels at each time of assessment. Depression levels at time 1 is positively correlated with time $2(\mathrm{r}=.529, p<.001)$, similarly, depression at time 2 correlated with time $3(\mathrm{r}=.435, p<.001)$, indicating that recipients, who reported depression at one time of assessment, tend to be more depressed at later times also. The study found that depression levels at each time appeared to be significant predictors of depression at next time of assessment. Depression at time 1 significantly predicted depression at time $2(\beta=.529$, $p=.000), \mathrm{F}(1,144)=54.927, p=.000, \mathrm{R}^{2}=.280$. Similarly, depression at time 2 predicted depression at time 2 $(\beta=.435, p=.000) \mathrm{F}(1,142)=33.135, p=.000, \mathrm{R}^{2}=.189$. In order to determine the direction of causality between depression and QoL over time, a cross lagged panel analysis was carried out.

\section{Path analysis}

Path analysis was used to investigate causal relationships between depression levels and overall QoL after a 
renal transplant. Longitudinal data from participants over a period of 15 months used to model lagged and cross-lagged paths over three time points of assessment after transplant, with a baseline, followed by an interval of six months (time 1) and one year (time 2). For the purpose of analysis, a cross lagged panel design was used. This design involves analysis of causal priority between two or more variables that are measured at each of the points in time. The aim is to estimate and test the strength of the relationship between the two sets of variables and determine causal priority.

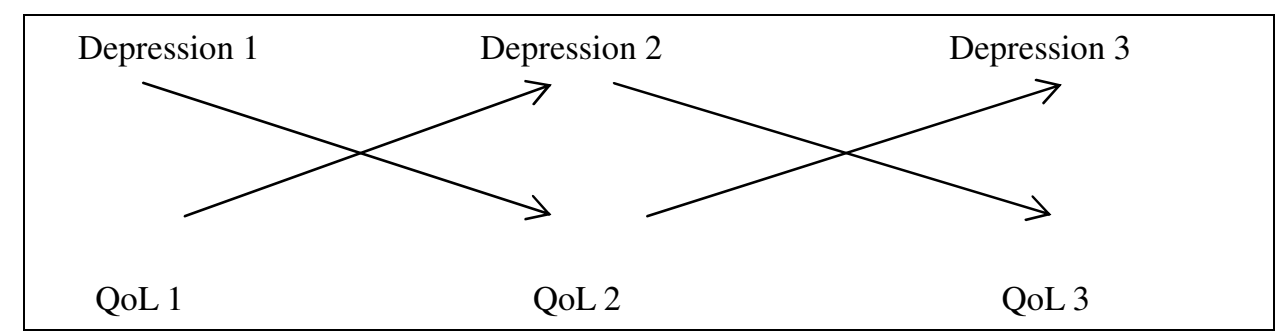

Figure 5. Cross lagged panel analysis of Depression and QoL

Table 15

Regression analysis for cross lagged panel analysis depression and QoL

\begin{tabular}{lccll}
\hline \multicolumn{1}{c}{ Predictors } & $\beta$ & $t$ & \multicolumn{1}{c}{$F$} & \multicolumn{1}{c}{ Outcome } \\
\hline Depression 1 & -.372 & -4.75 & $\mathrm{~F}(1,141)=22.596, p=.000$ & QoL 2 \\
Depression 2 & -.372 & -4.77 & $\mathrm{~F}(1,142)=22.822, p=.000$ & QoL 3 \\
QoL 1 & -.242 & -3.00 & $\mathrm{~F}(1,145)=9.055, p=.003$ & Depression 2 \\
QoL 2 & -.290 & -3.61 & $\mathrm{~F}(1,142)=13.087, \mathrm{p}=.000$ & Depression 3 \\
\hline
\end{tabular}

The cross lagged panel analysis showed that depression is a stronger predictor (time $1, \beta=-.242, p=.000$, \&time $2, \beta=-.290, p=.000$ ) of subjective QoL over time. QoL satisfaction appears to be predicted by depression levels. This is consistent with the correlations also indicating that recipients with increased depression tend to report a lower satisfaction with their QoL. Therefore, the causal direction favors depression as a predictor of consequent QoL.

\section{Discussion}

Life after transplantation improves health status and subjective well-being as compared to pre-transplant levels but the recipients are required to accept, adapt and cope with altered life style and new challenges to maintain their grafts. Recipients live with an uncertainty about their graft survival and longevity that is found as one of the major stressors in life post transplant (Pawar, Rathod, Chaudhry, Saxena, Saldanha, Riyali, \& Shrivastava, 2006). This uncertainty can contribute towards prevalence of depression. The psychological well being of the recipients is as important as the physical health status. There is consensus about the adverse effects of stress, anxiety and depression in worsening health outcomes after kidney transplant.

Many cross sectional studies have found that psychosocial factors in general and depression in specific, among RTRs decreases QoL and there is a need to identify high risk factors for vulnerable populations (Chisholm, Nievy, \& Nus 2007). The present longitudinal study analyzed the occurrence of depression among RTRs and found some positive findings with most RTRs reporting a minimum and mild level of depression. The findings reflect the efficacy of renal transplantation in a developing country like Pakistan, where majority of population does not benefit from quality health care services due to issues of affordability.

The study also found the contribution of demographic factors in influencing the occurrence of depression among RTRs. Age has been reported as a significant predictor of depression among transplant recipients (Szeifert et al., 2010), and our findings also revealed age as a significant predictor of depression consistently at each of three assessments. Comparisons showed older recipients to be more depressed than younger ones 
Kamran, F.

indicated by their mean scores on BDI II.

Gender has been found as a predictor of depression. Most studies associate female gender to increased level of depression (Novak et al., 2010). Our findings also confirmed that female recipients reported higher depression levels as compared to male recipients which are in consistency with previous findings, but the exact reasons of gender differences are still under debate. Some studies attribute it to sex roles in specific cultures but others negate it and it remains unclear why females are more depressed than males. Jofre, López-Gómez, Moreno, Sanz-Guajardo, and Valderrábano (1998) attributed it to low self esteem among females that added to their depression. Previous findings suggest that recipients currently living 'in a relationship' tend to be less depressed than single. Tsunoda, Yamashita, Kojima, and Takahara (2010) found that living alone is the best single predictor of future depression, and recipients living alone were more likely to be depressed as those living with others. Our findings are in consistency with previous research reflecting that marital status is a significant predictor of depression.

Finances are a major concern for the recipients because affordability of lifelong expensive immune-suppressants and compliance with regular follow-ups are mandatory issues post transplant. Socioeconomic status has been found as a significant predictor of psychological well-being among transplant recipients (Goldfarb-Rumyantzev, Koford, Braid, Chelamcharla, Habib, Wang, Lin, Shihab, \& Isaacs, 2006). Financial difficulties have been found to increase depression among RTRs. Studies found that depressed recipients did not have regular incomes (Tsunoda et al., 2010). Our findings are in confirmation with previous research since recipients with lower monthly family incomes appeared to be more depressed than those with more financial resources. Financial conditions significantly predicted depression levels at all 3 times in this longitudinal study.

Depression post transplant has been associated with comorbid conditions, such as kidney functioning, perceived financial situation, and marital status found to be significant and independent predictors of depression among RTRs (Szeifert, Molnar, Ambrus, Koczy, Kovacs, Vamos, Keszei, Mucsi, \& Novak, 2009). Our study also found demographic factors as significant predictors of depression after renal transplant. Existing literature suggests that a successful renal transplant is associated with improvement in depression (Pawar et al., 2006). Therefore, there is a need to investigate the occurrence and prevalence of depression among transplant recipients, particularly in developing countries where there are limited resources for both physical and mental health care.

Acknowledgements: This paper is funded by University of the Punjab, Lahore Pakistan.

\section{Conclusions}

These findings facilitate in identifying correlates of depression and its subsequent influence on over all QoL among renal transplant recipients in Pakistan. Longitudinal studies are required to identify vulnerable groups of recipients and refer them for depression screening that can be effective for better health outcomes. Such studies highlight the significance of psychosocial and demographic factors that play a significant role in causing mood symptoms such as depression which is considered to worsen kidney transplant outcomes. These findings can contribute towards developing psychological intervention management plans. This could contribute towards improvement in perceived health status, subjective well-being and over all QoL post transplant. 


\section{References:}

Andrews, F. M., \& Withey, S. B. (1976). Social indicators of well-being: Americans perceptions of life quality. New York: Plenum Press. <http://dx.doi.org/10.1007/978-1-4684-2253-5>

Akinlolu, O., Hanson, J. A, Wolfe, R. A, Leichtman, A. B, Lawrence, Y. A., \& Friedrich, K. P. (2000). Long-term survival in renal transplant recipients with graft function. Kidney International, 57, 307-313. $<$ http://dx.doi.org/10.1046/j.1523-1755.2000.00816.x>

Akman, B., Ozdemir, F. N., Sezer, S., Micozkadioglu, H., \& Haberal, M. (2004). Depression levels before and after renal transplantation. Transplant Proceedings, 36(1), 111-113. $<$ http://dx.doi.org/10.1016/j.transproceed.2003.11.021>

Goldfarb-Rumyantzev, A. S., Koford, J. K., Braid, B. C., Chelamcharla, M., Habib, A. N., Wang, B., J., Lin, S. J., Shihab, F., \& Isaacs, R. B. (2006). Role of socioeconomic status in kidney transplant outcome. Clinical Journal American Society Nephrology, 1, 313-322. <http://dx.doi.org/10.2215/CJN.00630805>

Baines, L. S., Joseph, J. T., \& Jindal, R. M. (2002). Emotional issues after kidney transplantation: a prospective psychotherapeutic study. Clinical Transplantation, 16(6), 455-460. $<$ http://dx.doi.org/10.1034/j.1399-0012.2002.02080.x >

Cameron, J. I., Whiteside, C., Katz, J., \& Devins, G. M. (2000). Differences in quality of life across renal replacement therapies: a meta-analytic comparison. American Journal of Kidney Disease, 35, 629-637. $<$ http://dx.doi.org/10.1016/S0272-6386(00)70009-6>

Cetingok, M., Hathaway, D., \& Winsett, R. (2007). Contribution of post-transplant social support to the quality of life of transplant recipients. Social Work in Health Care, 45(3), 39-56. $<$ http://dx.doi.org/10.1300/J010v45n03_03>

Cetingok, M., Winsett, R. P., \& Hathaway, D. K. (2004). A comparative study of quality of life among the age groups of kidney transplant recipients. Progress in Transplantation, 14(1), 33-38.

Caress, A. L, Luker, N. A., \& Owens, R. G. (2001). A descriptive study of meaning of illness in chronic renal disease. Journal of Advanced Nursing, 33, 716-727. $<$ http://dx.doi.org/10.1046/j.1365-2648.2001.01713.x>

Chang, C. L., \& Tzou, H. Y. (2001). Stress and adaptation process of kidney transplant recipients experienced acute rejection. Kidney and Dialysis, 13, 101-108.

Chen, K. H., Weng, L. C., \& Sheuan, L. (2009). Stress and stress-related factors of patients after renal transplantation in Taiwan: a cross-sectional study. Journal of Clinical Nursing, 19, 2539-2547. $<$ http://dx.doi.org/10.1111/j.1365-2702.2009.03175.x >

Chisholm, M. A, Spivey, C. A., \& Nus, A. V. (2007). Influence of economic and demographic factors on quality of life in renal transplant recipients. Clinical Transplantation, 21, 285-293. $<$ http://dx.doi.org/10.1111/j.1399-0012.2007.00640.x >

Clark, N. M., \& Becker, M. H. (1998). Theoretical models and strategies for improving adherence and disease management. In S. A. Shumaker, E. B. Schron, J. K. Ockene, \& W. L. McBee (Eds.), The handbook of health behavior change (pp. 15-21). New York: Springer.

Clark, N. M., \& Zimmerman, B. J. (1990). A social cognitive view of self regulated learning about health. Health Education Research, 5, 371-379. <http://dx.doi.org/10.1093/her/5.3.371>

Dobbels, F., Skeans, M. A, Snyder, J. J, Tuomari, A. V, Maclean, J. R., \& Kasiske, B. L. (2008). Depressive disorder in renal transplantation: an analysis of Medicare claims. American Journal of Kidney Disease, 51(5), 819-828. <http://dx.doi.org/10.1053/j.ajkd.2008.01.010>

Erogul, M., \& Sinert, R. H. (2008). Transplants renal. Retrieved January 11, 2011, from http://emedicine.medscape.com/article/778255

Fallen, M., Gould, D., \& Wainwright, S. P. (1997). Stress and quality of life in the renal transplant patient: A preliminary investigation. Journal of Advanced Nursing, 25, 562-570. $<$ http://dx.doi.org/10.1046/j.1365-2648.1997.1997025562.x>

Fisher, R., Gould, D., Wainwright, S., \& Fallon, M. (1998). Quality of life after renal transplantation. Journal of Clinical Nursing, 7, 553-563. <http://dx.doi.org/10.1046/j.1365-2702.1998.00189.x> 
Kamran, F.

Fiebiger, W., Mitterbauer, C., \& Oberbauer, R. (2004). Health-related quality of life outcomes after kidney transplantation. Health Quality of Life Outcomes, 2(1), 2. <http://dx.doi.org/10.1186/1477-7525-2-2>

Frey, G. M. (1990). Stressors in renal transplant recipients at six weeks after transplant. American Nephrology Nurses' Association Journal, 17, 442-446.

Edgell, E.T., Coons, S. J., \& Carter, W. B., et al. (1996). A review of health-related quality- of-life measures used in end-stage renal disease. Clinical Therapeutics, 18, 887-938. $<$ http://dx.doi.org/10.1016/S0149-2918(96)80049-X>

Gremigni, P., Bacchi, F., Turrini, C., Cappelli, G., Albertazzi, A., \& Bitti, P. E. (2007). Psychological factors associated with medication adherence following renal transplantation. Clinical Transplantation, 21(6), 710-715.

Goetzmanna, L., Saraca,N., Ambühlb, P., Boehlerb, A., Iranib, S., Muellhauptb, B., Nollb,G., Schleunigera, M., Schweglera, K., Buddeberga, C., \& Klaghofera, R. (2008). Psychological response and quality of life after transplantation: a comparison between heart, lung, liver, and kidney recipients. Swiss Med Weekly, 138(33-34), 477-483.

Jofré, R., López-Gómez, J. M., Moreno, F., Sanz-Guajardo, D., \& Valderrábano, F. (1998). Changes in quality of life after renal transplantation. American Journal of Kidney Disease, 32(1), 93-100. <http://dx.doi.org/10.1053/ajkd.1998.v32.pm9669429>

Johnson, C. D., Wicks, M. N., Milstead, J., Hartwig, M., \& Hathaway, D. K. (1998). Racial and gender differences in quality of life following kidney transplantation. Journal of Nursing Scholarship, 30, 125-130. <http://dx.doi.org/10.1111/j.1547-5069.1998.tb01266.x>

Karaminia, R., Tavallaii, S. A., Lorgard-Dezfuli-Nejad, M., Moghani Lankarani, M., Hadavand Mirzaie, H., Einollahi, B., \& Firoozan, A. (2007). Anxiety and depression: a comparison between renal transplant recipients and hemodialysis patients. Transplant Proceedings May, 39(4), 1082-1084.

Kimmel, P. L., Peterson, R. A., Weihs, K. L., Simmens, S. J., Alleyne, S., Cruz, I., \& Veis, J. H.(2000). Multiple measurements of depression predict mortality in a longitudinal study of chronic hemodialysis outpatients. Kidney International, 57, 2093-2098. $<$ http://dx.doi.org/10.1046/j.1523-1755.2000.00059.x >

Kuyken, W., Orley, J., Power, M. et al. (1995). The world health organization Quality of Life assessment (WHOQOL): Position paper from the world health organization. Social Science \& Medicine, 41, 1403-1409. <http://dx.doi.org/10.1016/0277-9536(95)00112-K>

Leung, D. K. C. (2003). Psychological aspects in renal patients. Peritoneal Dialysis International, 23(2), 590-592.

Liu, H., Feurer, I. D., Dwyer, K., Shaffer, D., \& Pinson, C. W. (2009). Effects of clinical factors on psychosocial variables in renal transplant recipients. Journal of Advanced Nursing, 65, 2585-2596. $<$ http://dx.doi.org/10.1111/j.1365-2648.2009.05111.x >

Lopes, A. A, Albert, J. M., \& Young, E.W. (2004). Screening for depression in hemodialysis patients: Associations with diagnosis, treatment, and outcomes in the DOPPS. Kidney International, 66, 2047-2053. <http://dx.doi.org/10.1111/j.1523-1755.2004.00977.x >

Muehrer, R. J., \& Becker, B. N. (2005). Life after transplantation: new transitions in quality of life and psychological distress. Seminars in Dialysis, 18(2), 124-131. $<$ http://dx.doi.org/10.1111/j.1525-139X.2005.18214.x >

Noohi, S., Khaghani-Zadeha, M., Javadipourb, M., Assarib, S., Najafia, M., Ebrahiminiaa, M., \& Pourfarziania, V. (2007). Anxiety and depression are correlated with higher morbidity after kidney transplantation. Transplantation Proceedings, 39(4), 1074-1078. $<$ http://dx.doi.org/10.1016/j.transproceed.2007.04.002>

Novak, M., Molnar, M. Z., Szeifert, L., Kovacs, A. Z, Vamos, E. P., Zoller, R., Keszei, A., \& Mucsi, I. (2010). Depressive symptoms and mortality in patients after kidney transplantation: a prospective prevalent cohort study. Psychosomatic Medicine, 72(6), 527-534. $<$ http://dx.doi.org/10.1097/PSY.0b013e3181dbbb7d >

Overbeck, I., Bartels, M., Decker, O., Harms, J., Hauss, J., \& Fangmann, J. (2005). Changes in quality of life 
after renal transplantation. Transplantation Proceedings, 37(3), 1618-1621.

<http://dx.doi.org/10.1016/j.transproceed.2004.09.019>

Pawar, A. A., Rathod, J., Chaudhury, S., Saxena, S. K., Saldanha, D., Ryali, V., \& Srivastava, K. (2006).

Cognitive and emotional effects of renal transplantation. Indian Journal of Psychiatry, 48, 21-26.

$<$ http://dx.doi.org/10.4103/0019-5545.31614>

Rocha, G., Poli deFigueiredo, C. E., d'Avila, D., \& Saitovitch, D. (2001). Depressive symptoms and kidney transplant outcome. Transplantation Proceedings, 33, 34 -24.

$<$ http://dx.doi.org/10.1016/S0041-1345(01)02476-9>

Szeifert, L., Molnar, M. Z., Ambrus, C., Koczy, A.B, Kovacs, A. Z, Vamos, E. P., Keszei, A., Mucsi, I., \& Novak, M.(2010) Symptoms of depression in kidney transplant recipients: A cross-sectional study. American Journal of Kidney Diseases, 55(1), 132-140. <http://dx.doi.org/10.1053/j.ajkd.2009.09.022>

Shah, V. S., Ananth, A., Sohal, G. K., Bertges-Yost, W., Eshelman, A., Parasuraman, R. K., \& Venkat, K. K. (2006). Quality of life and psychosocial factors in renal transplant recipients. Transplant Proceedings, 38(5), 1283-1285. <http://dx.doi.org/10.1016/j.transproceed.2006.03.027>

Tsunoda, T., Yamashita, R., Kojima, Y., \& Takahara, S. (2010). Risk factors for depression after kidney transplantation. Transplantation Proceedings, 42(5), 1679-1681.

$<$ http://dx.doi.org/10.1016/j.transproceed.2009.12.073>

Vamos, E. P, Mucsi, I., Keszei, A., Kopp, M. S., \& Novak, M. (2009). Comorbid depression is associated with increased healthcare utilization and lost productivity in persons with diabetes: A large nationally representative Hungarian population survey. Psychosomatic Medicine, 71(5), 501-507. 
Kamran, F. 